Having observed that ferritin levels fluctuate with episodes of inflammation we must establish whether this reflects $(a)$ a nonspecific (iron-independent) stimulation of the inflamed reticuloendothelial cell to produce the protein apoferritin or $(b)$ a genuine redistribution of iron from the serum, red cell, and possibly bone marrow compartments to the reticuloendothelial cell with the subsequent production of apoferritin. Both mechanisms could, of course, operate. Our data, derived from the study of serum, synovial fluid, and synovial membrane apoferritin concentrations, support the suggestion that both mechanisms are operating, but does not provide absolute proof. As we do not know if synovial fluid apoferritin contains iron we would prefer to describe what we measure, the protein, rather than what may or may not be inside this protein.

As to our "remarkable" statement that the haemoglobin and red cell indices serve as an index of iron stores in healthy subjects, I am prompted to remind $\mathrm{Dr}$ Bentley and his coauthors that "the depletion of haemoglobin iron is the most obvious and easily measurable consequence of iron deficiency. With the diminution of red cell mass a compensatory increase in plasma volume occurs and consequently the haemoglobin of the blood falls." The observation that the haemoglobin and red cell indices do not correlate with iron stores in normal, healthy subjects is neither surprising nor important in clinical practice, and is not contradicted by our article. My point is simple. There is no need to measure serum ferritin in a normal individual who is not anaemic, and rarely any need in one who is. There may be a need in patients with inflammation. Lower limits of "normality" established from "normal" populations are not relevant to the rheumatoid population.

David Blake

Royal National Hospital for Rheumatic Diseases,

Bath BA1 1RL Beutler E, Fairbanks VF. In: Jacobs A, Worwood M,
eds. Iron in biochemistry and medicine. Vol 2. London: Academic Press, 1980:394.

\section{Prophylaxis of acute mountain sickness}

SIR,-To compare the use of acetazolamide for acute mountain sickness with cinnarizine for seasickness, as is done by Drs A R Bradwell and J P Delamere (21 November, p 1402), is not to equate like with like because, as they point out, acute mountain sickness may be fatal whereas seasickness per se is not. In addition to the risks of acute mountain sickness, ascent to high altitude is an inherently dangerous activity because of environmental hazards. Therefore before the widespread use of acetazolamide as a prophylactic measure is advocated the overall risks of using it should be considered so as to ensure that they are less than those of not using it.

Acetazolamide certainly lowers the incidence of acute mountain sickness, ${ }^{12}$ and thus its use would appear to be indicated for high-altitude travellers. However, against this must be set any adverse effects, which may include the potential for people to ascend to situations whence evacuation or descent is more difficult should problems occur, whatever their cause. It would be an ironic tragedy if the indiscriminate use of acetazolamide by highaltitude travellers led to an iatrogenic increase in morbidity and mortality because they were better able to put themselves at risk. Careful thought should be given about which travellers are likely to benefit.

\section{Directorate of Army \\ Preventive Medicine, \\ Ministry of Defence,
London WC1V 6HD}

Birmingham Medical Research Expeditionary Society Mountain Sickness Study Group. Lancet 1981; $180-3$ Greene MK, Kerr AM, MacIntosh IB, Prescott RJ.

\section{Matricide}

SIR,-With reference to $\operatorname{Dr} D$ Chiswick's interesting review of matricide (14 November, p 1279), which is in essence a critical synopsis of my recently published paper, ${ }^{1}$ I would like to make a brief observation on the subject of matricide by daughters. Dr Chiswick states that matricide is "almost exclusively a crime of sons." Although very rare, matricide by daughters does occur.

The sister of the writer Charles Lamb (1775-1834), killed her mother in a fit of insanity. ${ }^{2}$ Medlicott gave a detailed clinical account of matricide by two adolescent girls in the setting of folie à deux. ${ }^{3}$ Rozycka and Thille $^{4}$ described 38 cases of patricide, parent murder. These include nine homicides committed by women, none of whom were considered psychotic. Unfortunately, the significance of the study is severely limited, as there is no differentiation between matricide and patricide. My survey of the census population of Broadmoor patients in January 1960 and all admissions up to December 1979 showed a total of 12 female patients who had killed their mothers. There appears to be little other clinical information on the topic and the pathological characteristics of this form of homicide remain largely to be determined.

Regional Psychiatric Centre (Prairies),
Saskatoon, Saskatchewan S7K 3X5,

C M GREEN

' Green CM. Med Sci Law 1981 ;21:207-14.

Lamb C. The letters of Charles Lamb. Vol 1. London: J M Dent and Sons, 1950.

Medlicott RW. Br J Med Psychol 1955;28:205-25.
Rozycka M, Thille Z. Psychiatr Pol 1972;6:159-68.

\section{Clinical value of serum immunoreactive} trypsin concentration

SIR,-The clinical evaluation of random measurements of serum immunoreactive trypsin levels by Dr W S J Ruddell and others (28 November, p 1429) suggested that the concentrations had a low specificity and sensitivity for pancreatic disease and did not reflect insufficiency in patients with proved chronic pancreatitis. In their discussion, however, the authors neglected to consider how the blood may show levels of immunoreactive trypsin in patients with pancreatic disease as well as in normal people.

Radioimmunoassay measures trypsinogen as well as active trypsin, and it is easy to think that when serum levels of immunoreactive trypsin are measured that it is trypsin rather than trypsinogen that is being estimated. It has also been shown ${ }^{12}$ (in studies that included the use of secretin-pancreozymin administration) that immunoreactive trypsin in the blood may be due to absorption from the duodenum and upper jejunum, and that this trypsin is then excreted in the bile and possibly the pancreatic juice in an endocirculation; in addition, excretion in the kidneys is assumed on the finding of raised levels of immunoreactive trypsin in chronic renal failure, ${ }^{3}$ presumably from impaired renal clearance.

From all this it seems clear that measuring random blood samples for immunoreactive trypsin from healthy controls, controls in hospital, and patients with chronic pancreatitis and pancreatic carcinoma with tests suggesting pancreatic disease is likely to prove unhelpful in the evaluation of patients with chronic pancreatic disease, as has now been confirmed. Concentrations of raised immunoreactive trypsin have been reported in acute pancreatitis $^{1}$ as well as in chronic renal failure. ${ }^{3}$ With my personal interest in acute pancreatitis ${ }^{4} \mathrm{I}$ should be fascinated to know how the raised levels occur in this condition; and whether they are due mainly to trypsinogen or to trypsin, and if the latter how it is activated; and also whether the cases of acute pancreatitis in which the raised levels are found are interstitial or haemorrhagic. Elias et al, ${ }^{1}$ using radioimmunoassay, reported raised serum immunoreactive trypsin levels in 14 patients with acute pancreatitis but did not indicate the type of pancreatitis or the ratio of trypsin to trypsinogen levels (neither of which would have been easy to determine). In my paper ${ }^{4}$ I hinted that there was evidence suggesting that with obstruction of the main pancreatic duct there might be raised blood levels of trypsinogen in parallel with those of amylase.

MiLo Keynes

University Department of Anatomy,

CB2 3DY

' Elias E, Redshaw M, Wood T. Lancet 1977;ii:66-8. of the British Society of Gastroenterology 1978;
of the Proceedings FC55 (March):33.

Lake-Bakaar G, McKavanagh S, Gatus B, 97-101.

+ Keynes WM. Ann Surg 1980;191:187-99.

SIR,-The paper by Dr W S J Ruddell and colleagues on the clinical evaluation of serum trypsin concentration as a screening test for pancreatic disease (28 November, p 1429) is a valuable demonstration of the limited value of this measurement for identifying or assessing the degree of pancreatic exocrine dysfunction.

The absence of a significant correlation between serum trypsin concentration and mean tryptic activity in their group of patients with chronic pancreatitis is in accordance with the result of a similar evaluation in patients with insulin-dependent diabetes. ${ }^{1}$ Although diabetic subjects have been shown to have both subnormal serum trypsin concentrations ${ }^{2}{ }^{3}$ and decreased exocrine pancreatic function, ${ }^{4}$ no significant correlation has been demonstrated between fasting serum trypsin values and pancreatic trypsin output stimulated by secretin and cholecystokinin-pancreozymin. ${ }^{1}$

It would be interesting to know, however, if any of the 18 patients in the present study who had subnormal serum trypsin concentrations had any clinical or biochemical evidence of glucose intolerance, in view of the observation that serum trypsin appears to decline with increasing duration of diabetes. ${ }^{1}$ It is surprising that the authors did not include this information in their otherwise detailed clinical data, as diabetes can, of course, be secondary to chronic pancreatitis.

There now seems little doubt that previous claims that serum trypsin concentration has a direct correlation with the pancreatic secretion 